\title{
Revealing the mysteries of thymoma
}

Thymic tumors (TTs) are rare neoplasms arising from thymic epithelial cells. In adults thymomas, thymic carcinomas and thymic neuroendocrine cancers are the most common TTs usually located in the anterior mediastinum. Thymomas account for about $50 \%$ of anterior and $20 \%$ of all mediastinal tumors. There are no known risk factors for these tumors; however, there is a strong association with myasthenia gravis and other paraneoplastic syndromes (PNS) and autoimmune disorders (AID) (1).

Thymomas and other TTs typically present with one of the three major scenarios: as an incidental finding on imaging in an asymptomatic patient, with local (thoracic) symptoms, or with symptoms due to PNS or AID. The most common PNS associated with TTs is myasthenia gravis, but a wide range of other disorders with PNS and AID have been reported. Up to one-half of patients with thymoma have symptoms consistent with myasthenia gravis $(1,2)$.

Key elements in the differential diagnosis of an anterior mediastinal mass include not only thymoma and thymic carcinoma, but also retrosternal thyroid, lymphoma, and mediastinal germ cell tumor. Optimal evaluation and diagnosis of mediastinal tumors generally require comprehensive clinical, radiologic and histologic investigations. The clinical approach includes consideration of several factors including detailed symptomatology and associated conditions of PNS and AID. CT is essential to determine the mediastinal location and intrathoracic extent of the tumor whereas MRI and PET-CT are used on a selective basis depending on the case. Histological confirmation before treatment is necessary in locally advanced or unresectable TTs (1-3).

Following imaging findings that suggest a tumor of thymic origin, the definitive diagnosis of a TT requires histologic confirmation. For a TT amenable to complete resection, the initial step in the management is surgical resection, which also enables the histologic diagnosis. For patients with unresectable tumor due to locally advanced or metastatic disease, or those who are inoperable due to old age or comorbidity, a histologic diagnosis by core needle biopsy, other minimally invasive procedure, or surgical biopsy is required prior to treatment decision (3-6).

The histologic classification of TTs is performed according to the WHO classification system (7). For staging which is based on the extent of the primary tumor and presence of invasion into adjacent structures and/or dissemination, generally the Masaoka staging system $(1,4,6)$ or the new IASLC/ITMIG staging system (8th edition of the AJCC TNM classification) (8) is used.

Surgery is the standard of care for resectable TTs. For patients in whom a complete resection is not feasible as the initial step, multimodality treatment incorporating preoperative chemotherapy, postoperative chemotherapy, and/or postoperative radiotherapy may be indicated. If neoadjuvant chemotherapy allows for a partial or complete response, such disease is considered potentially resectable. For unresectable disease chemotherapy, radiotherapy, or chemoradiotherapy is considered $(1,3,4,6)$. As for immunotherapy, further research and clinical experience in treatment with immune checkpoint inhibitors is needed to determine the definite role of immunotherapy in patients with advanced TTs (9).

Morbidity and mortality in TTs are determined by (I) advanced stage or oncologically uncontrolled disease, (II) serious conditions associated with AID or PNS, (III) impaired immunocompetence and AID or PNS resulting in infections or secondary malignancies, and (IV) therapy-related complications $(3,4,10)$.

This special issue of the Fournal of Thoracic Disease focused on thymoma presents up-to- date and extensive reviews spanning from the epidemiology to the genetics and biology and to the diagnostic and therapeutic modalities. Similarly to other rare tumors, thymoma has been largely understudied for years. However, in the last few years there has been significant research performed particularly in the field of molecular biology of these tumors. Several important and novel advancements in genetics and molecular biology are discussed in two chapters of this issue. Furthermore, the principles of current care including all novelties regarding diagnostic and treatment modalities are provided in several other chapters.

With the pleasure of being the editors, we thank all of our colleagues for their efforts in constituting this focused issue with their excellent reviews and anticipate that the readers will enjoy reading and benefit from them. 


\section{Acknowledgments}

Funding: None.

\section{Footnote}

Provenance and Peer Review: This article was commissioned by the editorial office, Fournal of Thoracic Disease for the series "Thymoma". The article did not undergo external peer review.

Conflicts of Interest: Both authors have completed the ICMJE uniform disclosure form (available at: http://dx.doi.org/10.21037/ jtd-2019-thym-15). The series "Thymoma" was commissioned by the editorial office without any funding or sponsorship. DJ served as the unpaid Guest Editor and serves as an unpaid editorial board member of Journal of Thoracic Disease from Feb 2019 to Jan 2021. SB served as the unpaid Guest Editor of the series. The authors have no other conflicts of interest to declare.

Ethical Statement: The authors are accountable for all aspects of the work in ensuring that questions related to the accuracy or integrity of any part of the work are appropriately investigated and resolved.

Open Access Statement: This is an Open Access article distributed in accordance with the Creative Commons AttributionNonCommercial-NoDerivs 4.0 International License (CC BY-NC-ND 4.0), which permits the non-commercial replication and distribution of the article with the strict proviso that no changes or edits are made and the original work is properly cited (including links to both the formal publication through the relevant DOI and the license). See: https://creativecommons.org/licenses/by-nc$\mathrm{nd} / 4.0 \%$.

\section{References}

1. Scorsetti M, Leo F, Trama A, et al. Thymoma and thymic carcinomas. Crit Rev Oncol Hematol 2016;99:332-50.

2. Sperling B, Marschall J, Kennedy R, et al. Thymoma: a review of the clinical and pathological findings in 65 cases. Can J Surg 2003;46:37-42.

3. Tomaszek S, Wigle DA, Keshavjee S, et al. Thymomas: review of current clinical practice. Ann Thorac Surg 2009;87:1973-80.

4. Detterbeck FC, Zeeshan A. Thymoma: current diagnosis and treatment. Chin Med J (Engl) 2013;126:2186-91.

5. Yue J, Gu Z, Yu Z, et al, Members of the Chinese Alliance for Research in Thymomas. Pretreatment biopsy for histological diagnosis and induction therapy in thymic tumors. J Thorac Dis 2016;8:656-64.

6. Ried M, Marx A, Götz A, et al. State of the art: diagnostic tools and innovative therapies for treatment of advanced thymoma and thymic carcinoma. Eur J Cardiothorac Surg 2016;49:1545-52.

7. Travis WD. The 2015 WHO classification of lung tumors. Pathologe 2014;35 Suppl 2:188.

8. Ried M, Eicher MM, Neu R, et al. Evaluation of the new TNM-staging system for thymic malignancies: impact on indication and survival. World J Surg Oncol 2017;15:214.

9. Yokoyama S, Miyoshi H. Thymic tumors and immune checkpoint inhibitors. J Thorac Dis 2018;10:S1509-15.

10. Lippner EA, Lewis DB, Robinson WH, et al. Paraneoplastic and therapy-related immune complications in thymic malignancies. Curr Treat Options Oncol 2019;20:62. 


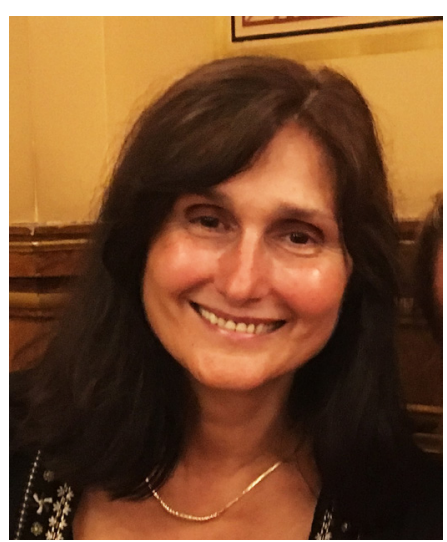

Dragana Jovanovic

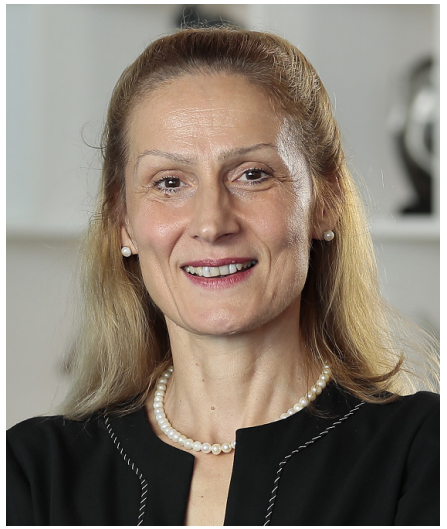

Semra Bilaceroglu

Dragana Jovanovic, $\mathbf{M D}, \mathbf{P h D}^{1}$

${ }^{1}$ Professor of Pulmonology, Thoracic Oncology and Palliative Medicine, Internal Medicine Clinic "Akta Medica”, Belgrade, Serbia;

(Email:draganajv@yahoo.com) Semra Bilaceroglu, $\mathbf{M D}^{2}$

${ }^{2}$ Professor of Pulmonology, Dept. of Pulmonology, University of Health Sciences, Dr. Suat Seren Training and Research Hospital for Thoracic Medicine and Surgery, Izmir, Turkey.

(Email: s.bilaceroglu@gmail.com)

Submitted Feb 11, 2020. Accepted for publication May 13, 2020. doi: $10.21037 /$ jtd-2019-thym-15

View this article at: http://dx.doi.org/10.21037/jtd-2019-thym-15

Cite this article as: Jovanovic D, Bilaceroglu S. Revealing the mysteries of thymoma. J Thorac Dis 2020;12(12):7515-7517. doi: 10.21037/jtd-2019-thym-15 